\title{
Representaçôes sociais do consumo de carne em Belo Horizonte
}

I 1 Guilherme Santiago de Barros, ${ }^{2}$ José Newton Coelho Meneses,

${ }^{3}$ José Ailton da Silva I

Resumo: O presente estudo objetivou identificar as representações sociais do consumo de carne em Belo Horizonte, MG, adotando-se a metodologia qualitativa. Foram feitas entrevistas semiestruturadas com 34 frequentadores do Mercado Central de Belo Horizonte, as quais foram analisadas por meio da técnica de análise de conteúdo. Verificou-se que, majoritariamente, o gosto pela carne é representado como uma construção cultural e que ela ocupa o papel central das refeições, servindo, inclusive, de elemento para coesão social. O hábito de abstinência da carne no período da Quaresma mostrou-se esvaziado do significado original, perpetuando-se como simples tradição ou norma católica. Observou-se que a carne vermelha em várias ocasiões tem a ela atribuída, exclusivamente, o significado de "carne". Quanto à saúde, houve grande diversidade de representaçôes, sendo o consumo de carne representado como saudável ou não saudável dependendo da circunstância. Igualmente, quando em evidência seu preço, ela transitava de item necessário para opcional. A carne foi fortemente identificada como fonte de proteína e a carne branca considerada mais saudável que a vermelha. A de porco foi representada como gordurosa e potencial transmissora de doenças. As representaçôes sociais do consumo da carne, em geral, mostraram-se independentes das representações dos animais de produção. Espera-se dos profissionais de saúde a consideração da complexidade e importância do fator cultural do consumo da carne para não correrem o risco de suas ações serem pautadas num tecnicismo reducionista. Os resultados obtidos também podem ser úteis tanto para a indústria da carne quanto para defensores do seu não consumo.

\author{
1 Médico Veterinário, mestre \\ em Ciência Animal, área de \\ concentração Epidemiologia, \\ pela Universidade Federal de \\ Minas Gerais (UFMG). \\ Endereço eletrônico: \\ guilhermesbarros@gmail.com \\ 2 Doutor em História, professor \\ adjunto do departamento de \\ História da UFMG. \\ Endereço eletrônico: \\ jnmeneses@uol.com.br \\ ${ }^{3}$ Doutor em Ciência Animal \\ professor associado do \\ departamento de Medicina \\ Veterinária Preventiva da \\ Escola de Veterinária da UFMG. \\ Endereço eletrônico: jasilva@ \\ vet.ufmg.br
}


A partir do século XIX, as ciências modernas relacionadas à nutrição desenvolveram-se com caráter multidisciplinar, reunindo avanços em distintos ramos das ciências naturais. Entretanto, possíveis contribuições das ciências humanas foram negligenciadas, uma vez que o enfoque era majoritariamente biológico (CARNEIRO, 2003). Já recentemente, segundo Silva et al. (2010), as institucionalizadas áreas da Nutrição e da Saúde Coletiva vêm se dedicando a compreender a alimentação como fenômeno humano, resultando num crescente intercâmbio entre os campos biomédicos e humanísticos.

Segundo Maciel (2004), a alimentação é mais que um elemento da "cultura material”, pois implica em representações e imaginários, e envolve escolhas, classificações e símbolos que organizam as diversas visões de mundo no tempo e espaço. Tendo isso em vista, DaMatta (1984; 1987) e Gonçalves (2004) fazem distinção entre os termos alimento e comida. Enquanto o alimento tem a ver com um corpo concebido em termos estritamente fisiológicos, a comida está associada a um corpo que é culturalmente formado.

Segundo Woortmann (2004), a comida por excelência é a carne, e não devido apenas ao seu preço. O componente central das refeiçôes constitui-se sempre num alimento de origem animal, notadamente nas refeiçôes cerimoniais e/ou públicas. Fiddes (1991) afirma que, em diferentes contextos, culturas, grupos sociais e períodos históricos, a carne é soberana. Na hierarquia da comida, ela estaria no topo, particularmente a carne vermelha, pelo fato do status e do significado da carne estarem essencialmente ligados a ela. Com menor status estariam as carnes brancas (frango e peixe) e, abaixo, outros produtos de origem animal (ovos e queijo). Mais abaixo estariam os vegetais, considerados insuficientes para formar uma refeição e, portanto, representando apenas um papel auxiliar.

Considerando esse quadro complexo do processo cultural da alimentação, em seus amplos aspectos, e a significância simbólica da carne na alimentação humana, com este trabalho pretendeu-se explorar a dimensão do seu consumo, extrapolando-se a fronteira do biológico, e conhecer valores relacionados e representações simbólicas envolvidas em tal prática alimentar. 


\section{Metodologia}

Adotou-se como alicerce para a realização do estudo a metodologia qualitativa e a teoria das representações sociais (MOSCOVICI, 2003). Segundo Garcia (1994), tal teoria seria adequada para o entendimento do convívio de aspectos simbólicos presentes nas práticas alimentares, uma vez que considera a imbricação entre natureza e cultura.

\section{Local do estudo}

O presente trabalho ${ }^{1}$ foi realizado em Belo Horizonte, MG, especificamente no Mercado Central de Belo Horizonte. O Mercado Central, principal mercado popular da cidade, carrega um forte significado histórico e cultural, com destaque para os elementos relacionados aos hábitos alimentares e à gastronomia. A despeito das transformações urbanas relativamente recentes, o Mercado Central mantém-se vibrante econômica e culturalmente, sendo um dos principais pontos de referência de Belo Horizonte e da cultura belorizontina, como também da cultura mineira em geral (FILGUEIRAS, 2006).

\section{Amostra}

Para o desenvolvimento da pesquisa, foram entrevistados 34 frequentadores do Mercado Central, selecionados de forma intencional no próprio Mercado. Esse número foi definido ao longo da pesquisa pela estratégia de saturação, que, segundo Rosa e Arnoldi (2006), parte da premissa que mais entrevistas não se fazem necessárias quando não se encontram mais dados adicionais à solução do tema em questão. De modo a garantir maior heterogeneidade à amostra, as entrevistas foram realizadas nos vários dias da semana, abrangendo manhã e/ou tarde, variando sempre o local do mercado para abordagem das pessoas.

A caracterização da amostra como intencional dá-se pela opção em não abordar indivíduos que estivessem conversando, efetuando alguma compra, acompanhados por mais de uma pessoa, deslocando-se com rapidez ou carregando sacolas ou objetos pesados e/ou volumosos. Todo entrevistado deveria ter idade igual ou superior a 18 anos e não ser turista. 
Dos 34 entrevistados, 20 foram do sexo masculino, e 14, do feminino. A idade média foi de 40 anos, variando entre 22 e 67 anos.

\section{Entrevistas}

As entrevistas foram realizadas no período entre abril e outubro de 2009 no próprio Mercado Central. A modalidade de entrevista utilizada foi a semiestruturada, uma vez que, segundo Rosa e Arnoldi (2006), é adequada para a avaliação de crenças, sentimentos, valores, atitudes, razões e motivos acompanhados de fatos e comportamentos. Para tanto, foi elaborado um roteiro de entrevista contendo treze perguntas que abordavam temas como: motivação e ocasiôes para consumo, função da carne na alimentação, quantidade e tipos consumidos e preocupação com a sua origem. $\mathrm{O}$ roteiro teve a finalidade de extrair representações sociais do consumo de carne que dizem respeito aos mais variados aspectos. As perguntas, no entanto, serviram apenas de guia para o entrevistador, que teve plena liberdade para propor questões não planejadas previamente quando julgava conveniente.

O roteiro construído foi utilizado apenas em entrevistas com pessoas que consumiam carne. No caso das pessoas ditas vegetarianas (três entrevistados), ou seja, que não consumiam carne, não havia roteiro pré-estabelecido.

As entrevistas só tinham início após o entrevistador fazer uma breve explanação sobre a pesquisa e seus objetivos, e, se houvesse consentimento da pessoa a ser entrevistada, após leitura e assinatura do Termo de Consentimento Livre e Esclarecido. Todas as entrevistas foram gravadas na íntegra utilizando-se um gravador digital.

\section{Análise das entrevistas}

A análise das entrevistas foi norteada pela técnica de análise de conteúdo descrita por Bardin (2008), e organizou-se em três etapas: pré-análise (organização do material e transcrição das entrevistas na íntegra), exploração do material (leitura exaustiva e categorização temática) e tratamento dos resultados e interpretação.

O estudo foi desenvolvido de acordo com a Resolução no 196/96 do Conselho Nacional de Saúde e aprovado pelo Comitê de Ética em Pesquisa da Universidade Federal de Minas Gerais (ETIC 550/08). 


\section{Consumo e gosto pela carne: cultura ou instinto?}

Canesqui e Garcia (2005) apontam a alimentação como um ato necessariamente modelado pela cultura. Segundo Mintz (2001), o gosto do ser humano pelas substâncias não é inato, forja-se no tempo e entre os interesses econômicos, os poderes políticos, as necessidades nutricionais e os significados culturais. Indo ao encontro dessa ideia, percebeu-se na maioria dos discursos a representação do consumo de carne e o gosto por ela como construções culturais. O costume e a cultura são assinalados como determinantes para a adoção desse hábito alimentar.

Pesquisador: "Por quais motivos come carne?"

[...] eu gosto e acho que faz parte da nossa cultura comer. (Entrevistado 03 - E03)

É o costume, hábito, né? Criação, né? Costume. Não tem outro motivo sem ser esse não. (E06)

Muito embora a consideração da cultura como determinante do consumo de carne tenha sido mais frequente, na fala de dois entrevistados, identifica-se a ideia de que o consumo desse alimento está relacionado ao instinto e a uma necessidade intrínseca ao organismo humano de comer a carne.

Pesquisador: "Por quais motivos [come carne]?"

Por vontade, por instinto, vontade própria, assim, por vontade de comer, entendeu? (E08)

(...) É questão da saúde. Fazer bem, pela necessidade do corpo em comer carne. (E13)

Ainda, no discurso de uma das entrevistadas, observa-se a convivência dessas duas ideias. $\mathrm{O}$ consumo da carne seria determinado tanto pelo costume familiar quanto por uma necessidade biológica inerente ao corpo.

Eu acho que pelo costume da minha família. Do costume que a gente tem de alimentar com carne, mas eu não como direto, não. Tanto que eu sinto muito mais falta de verdura do que carne, mas às vezes meu organismo pede. (E10)

\section{O gosto pela carne}

Mesmo havendo exceções, em geral, a carne foi apontada como alimento de grande agrado ao paladar. O sabor dela é tido como grande fonte de prazer. Chama atenção, em alguns casos, o forte apego demonstrado ao seu consumo, 
revelado pela obrigatoriedade da sua presença no ato de comer, seja este solitário ou em grupo. De fato, de acordo com Rial (2004), para muitas culturas, a presença da carne é fator importante para que uma ocorrência alimentar seja considerada refeição. Fiddes (1991) afirma que, em diferentes contextos, culturas, grupos sociais e períodos históricos, a carne é soberana, sendo muitas vezes considerada a comida "verdadeira".

E14: Ahn, de manhã, no almoço, na janta... Não como sem carne, não.

P: Então se você for num almoço na casa de alguém e não houver carne, como é que vai ser?

E14: Difícil. Ah, pra falar verdade, eu não como mesmo, não.

P: Não come?

E14: Mas de jei... nem vou fazer comida quando não tem carne. Nem, de jeito nenhum. Não, lá em casa já é avisado já: se não tem carne eu não vou fazer comida. Só vou se tiver carne. Carne e verdura, lógico, né? Eu acho que os dois faz parte, mas se não tiver um pedacinho de carne, meu filho, não tem comida, não.

Percebe-se que, na hierarquia da comida, como observa Fiddes (1991), a carne realmente ocupa o topo, sendo a comida preferida e principal.

P: Qual a função da carne na sua alimentação?

E08: Principal. Alimento sem carne, por exemplo, se for pra mim comer um arroz com feijão não vai descer como se tivesse comendo com a carne. Entendeu? A carne é como se fosse um... é... seria um pouco a mais, daria um sabor melhor ao alimento, faria o alimento ter um pouco mais de sabor.

\section{O que é carne}

Segundo Fiddes (1991), o status e o significado da carne estão essencialmente ligados à carne vermelha. Durante as entrevistas, isso ficou evidente em algumas situações em que a carne de frango e de peixe não foram consideradas como sendo carne, acontecendo o mesmo com a linguiça, produto derivado da carne. Em um dos casos, mesmo sendo alertado de que a pergunta tratava de carnes em geral, e não somente da vermelha, o entrevistado excluiu o peixe da categoria de carnes.

P: E se fosse numa festa que não tivesse carne?

E32: Pode ser, a gente come outra coisa: pizza, frango. Carne que você fala é em geral, né, ou é só de boi?

P: Não, carne em geral. Tem alguma ocasião que você não come carne? 
E32: Quando vou pescar.

P: Por quê?

E32: Porque lá é o peixe.

E linguiça não é muito meu forte, não. Mas mesmo assim acho que linguiça não é muito assim carne, não, mas é feito de carne também. (E07)

\section{Carne e comensalidade}

Segundo Ishige (1987), as refeições feitas em comum reforçam o grupo e contribuem para coesão. Partilhar a refeição é igualmente partilhar sensações, razão pela qual, em numerosas sociedades, as celebrações rituais são acompanhadas por banquetes, ocasiōes nas quais se reforçam laços antigos ou criam-se novos. A partir da análise das entrevistas, pode-se sugerir que a carne ocupa papel central nas reuniōes e eventos comemorativos, proporcionando momentos importantes de coesão social. Evidencia-se nessa observação que a carne, além de cumprir funções biológicas, atende também a funçōes sociais. Woortmann (2004) atenta para o fato de um alimento de origem animal sempre ocupar a centralidade nas refeições cerimoniais ou públicas. O consumo de carne nessas ocasiōes mostrouse ser maior que o habitual, inclusive sendo incentivado pelo grupo.

Às vezes, quando eu como carne que eu não gosto, às vezes é por incentivo dos amigos. A gente está num barzinho, vai pra um churrasco, uma coisa assim, aí tá rolando... às vezes você nem está com vontade de comer uma carne, mas você acaba comendo. (E24)

P: Em que ocasiōes você come carne?

E13: Sempre, não tem ocasiôes especiais. Apesar de que às vezes tem a comemoração, churrasco, é um hábito assim, né, tem aquela comemoração e a carne é colocada como celebrar, para celebrar, mas eu como carne em qualquer situação, quase todas as refeições.

\section{Restrição religiosa}

Apesar de existirem inúmeras restrições ao consumo da carne de motivação religiosa, apenas uma delas foi evidenciada nesta pesquisa: a abstinência de carne na Quaresma ligada ao catolicismo. Algumas vezes, no entanto, ela apareceu como simples tradição, não havendo importância o significado religioso, apesar 
do reconhecimento de sua origem, e sendo praticada inclusive por não católicos. Muitos dos entrevistados afirmaram seguir essa restrição e houve grande variação no período em que ela se dá: por toda a Quaresma, em todas as sextas-feiras da Quaresma, por toda a Semana Santa, na Sexta-Feira da Paixão e na Quarta-Feira de Cinzas, ou apenas na Sexta-Feira da Paixão.

Segundo Strong (2004), sob influência principalmente judaica, o jejum voluntário tornou-se entre os cristãos um aspecto relacionado ao caminho para a perfeição. Aos poucos essa prática foi sistematizada pela Igreja Católica, sendo inicialmente praticada apenas da Sexta-Feira Santa à manhã de Páscoa e, posteriormente, estendendo-se por toda a Quaresma.

Ainda segundo o autor, o jejum, redução global da quantidade de comida, passou a ser praticado sob a forma de abstinência de carne devido a uma reinterpretação feita por leigos, que a assumiram como símbolo de violência, morte, e todas as formas de corporeidade e sexualidade. Entretanto, não foi identificada tal representação da carne nas entrevistas. Os motivos para a prática da abstinência surgiam ora como uma regra da Igreja, que deveria ser cumprida por todo bom católico, ora por determinação cultural e reprodução de uma tradição.

Porque eu sou católica e respeito, né, a Igreja. (E15)

Eu sou evangélica, entendeu? Eu não como por causa da tradição dos meus pais, porque diz que na Sexta-Feira da Paixão, a carne, se a gente comer carne por abuso, a gente se...ah, sei lá, diz que acontece alguma coisa com a gente, mas eu não acredito nisso, não. (E31)

Notou-se em algumas falas que a abstinência da carne resume-se à restrição da carne vermelha, uma vez que a de peixe é consumida livremente, funcionando até mesmo como substituta da "carne". Como já discutido, o significado da “carne" está essencialmente relacionado à carne vermelha.

Tendo essa influência dos antepassados, das pessoas mais velhas, a gente adquiriu esse hábito e aí não comer, troca pelo peixe ou pelo ovo e assim vai. (E30)

\section{O local da compra}

A preocupação com a origem da carne consumida questionada nas entrevistas, quando existe, manifesta-se geralmente na escolha do local de compra do produto. Quando ele é o açougue, essa escolha se dá pela familiaridade com o açougueiro, em relação ao qual o tempo de convívio e a confiança depositada em 
sua figura asseguram a qualidade da carne oferecida. Ainda, segundo um dos

entrevistados, diferentemente do ocorrido em açougues, a beleza da apresentação das carnes em supermercados, com cor bonita, cor vermelha, é reflexo da adição de produtos químicos indesejáveis. Em outra percepção, quando o local de escolha é o supermercado, a motivação se dá pela crença de que, devido ao maior porte, a preocupação por parte do estabelecimento com a segurança e a qualidade da carne oferecida é maior, e que ainda há fiscalização mais rigorosa pelo Estado. Outro fator que mostrou ter influência na decisão de compra da carne em supermercados foi a política de ofertas realizadas nesses locais.

A carne, a gente compra com uma pessoa conhecida, um açougueiro que orienta e fala qual a melhor parte. Só isso. Eu não compro em qualquer lugar não. (E15)

[...] eu procuro comprar carne só em supermercado, porque eu imagino que supermercado é mais fiscalizado que açougue. (E26)

\section{Carne, o produto de animais}

Raramente, durante a pesquisa, perceberam-se, nas falas dos entrevistados, elementos que levassem a associar a carne ao abate de animais. Tal observação sugere que as representaçôes sociais do consumo de carne, de modo geral, são independentes das representações dos animais.

Todavia, em três entrevistas, duas formas de pensamento descritas por Francione (1996), relacionadas à maneira como o ser humano interage com os outros animais, foram identificadas. A primeira refere-se à visão "bem-estarista", a qual prega que os animais devem ser tratados "humanitariamente", e não devem estar sujeitos ao sofrimento desnecessário. Essa posição assume a legitimidade no tratamento instrumental dos animais como meios para fins humanos, desde que haja ressalvas garantidas. Por exemplo, o uso de animais em experimentos biomédicos e o abate de animais para consumo humano são aceitáveis, desde que essas atividades sejam conduzidas de forma "humana".

Já a teoria dos direitos animais confronta a visão anterior, considerando que animais não humanos, assim como os humanos, possuem um valor inerente que deve ser respeitado. A visão dos direitos reflete uma mudança na vaga obrigação da ação "humanitária" para a teoria da justiça, que rejeita o status dos animais como propriedade e a correspondente hegemonia dos humanos sobre os outros animais. A teoria dos direitos animais não aceita o uso de animais para experimentos 
ou para consumo humano, não porque simplesmente essas atividades causam sofrimento aos animais, mas porque esse uso viola as obrigações fundamentais de justiça que possuímos em relação os animais não humanos.

E07: [...] Então, igual essas carnes assim de baby beefassim eu já não gosto muito de comer "por causa que" você pensa assim nos bezerrinhos, tadinhos dos bezerrinhos. Agora, as outras carnes, eu nunca parei pra pensar isso não.

P: Você falou que tem dó dos bezerrinhos. E dos touros e das vacas, enfim, dos animais adultos, por que não tem o mesmo sentimento?

E07: Eu acho que é porque eles não foram tão maltratados assim na hora de cuidar. Igual uma professora minha uma vez passou um vídeo lá falando como é que é feita a carne de vitela lá que o bezerro fica preso num cubículo assim pra não conseguir mexer. Aí eu tenho esse sentimento assim. Para não criar músculos. E os outros eu acho que não foram tão maltratados assim na hora da criação. Ah, sei lá, não tenho esse mesmo sentimento.

P: Por quais motivos você não come carne?

E27: Saúde e a facilidade de comer outras coisas e não precisar de exploração dos animais. Não que... você também explora as pessoas nas plantações, no latifúndio, a mesma coisa. Só que como você pode substituir, como é tranquilo de substituir a carne então eu prefiro substituir a carne do que ficar comendo, porque não é tão necessária hoje em dia com o avanço da humanidade.

Percebe-se que, no primeiro discurso, há uma preocupação com a forma como os animais são tratados. Já no segundo, a exploração dos animais não humanos é questionada, inclusive sendo comparada à humana, o que traz a ideia de que tanto animais humanos e não humanos são detentores de direitos.

\section{Consumo de carne e saúde}

As representações sociais do consumo de carne que dizem respeito à saúde foram variadas e distintas. Este foi representado como: um hábito saudável e imprescindível; saudável, mas prescindível; necessário, mas com potencial danoso; ou desnecessário e danoso. Segundo Moscovici (2003), longe de serem um antídoto contra as representações sociais, as ciências, na verdade, geram, agora, tais representações. Na medida em que as teorias, as informaçōes e acontecimentos se multiplicam, os mundos devem ser duplicados e reproduzidos a um nível mais imediato e acessível. A ciência, antes, era baseada no senso comum, e fazia-o menos comum; mas, agora, senso comum é a ciência tornada comum.

Sendo assim, levando-se em consideração que não há, no meio científico, um consenso sobre a recomendação ou não do consumo de carne para benefício 
da saúde humana, essa variedade de representações sociais é esperada. $\mathrm{Na}$ literatura científica, trabalhos que exaltam as propriedades nutricionais da carne e reafirmam sua importância na alimentação humana convivem com diversos outros que relacionam o seu consumo com um maior risco de aparecimento de doenças como câncer, diabetes e doenças cardiovasculares, apontando as dietas vegetarianas bem planejadas como plenamente possíveis e saudáveis. Entretanto, para explicarmos o surgimento do consumo de carne como saudável e não saudável num mesmo discurso, devemos recorrer a Garcia (1997a; 1997b), que mostra que as práticas alimentares que estão de alguma forma orientadas por um viés disciplinar (a preocupação com a saúde neste caso) não serão o cumprimento linear desse princípio. Oscilações conflituosas do comportamento alimentar manifestam-se em representações edificadas, ora pela preocupação com a saúde, ora pelo desejo, adequando-se, desse modo, ora à saúde e ora ao paladar.

[...] As duas funçôes que eu tinha citado: a função de me dar prazer em saborear a carne e de me dar condições de saúde. É um hábito saudável o consumo de carne para mim. (E13)

Uai, porque se você não comer carne fica faltando algum nutriente pra poder complementar a alimentação. (E33)

P: Por quais motivos [come carne]?

E24: Primeiro porque eu gosto realmente. E segundo por causa de saúde. Eu sei que a carne tem muitas proteínas.

(...)

P: E tem algum motivo especial para você não consumir muito, consumir pouco?

E24: Preocupação com a saúde.

E outra também que eu vi que o não consumo de carne talvez possa fazer com que sua qualidade de vida seja melhor. (E02)

P: Então você acha que se você parar de comer carne, por exemplo, vai te causar algum transtorno?

Não, de forma alguma. Se eu parar, de forma alguma. (E04)

Não, vai fazer é bem. Comer carne demais faz mal, você tem que comer moderadamente. (E23)

A carne foi apontada por três entrevistados como sendo um alimento que interferiria negativamente na digestão. Além disso, é representada como potencial fonte de risco à saúde por conter "toxinas", "hormônios" e "antibióticos". Tal representação possui fundamento prático, uma vez que as carnes em geral podem 
conter resíduos de antibióticos e outros aditivos, caso não haja o uso prudente e racional destes no processo de criação dos animais destinados ao consumo humano.

Porque eu sei que a carne demora a ser digerida. Eu sinto mal estar. Não assim de sentir muito mal, mas mais cansada. Então eu evito um pouco de comer. E também por causa da... eu sei das toxinas que vêm junto com as carnes. Questão de hormônio, é... questão hormonal mesmo, né, que nas carnes que a gente come de açougue assim tem muito hormônio. Carne de frango, carne de boi, mesmo.(...)Mesmo questão na hora do abatimento do boi, da vaca e tal ele sofre uma tensão muito grande, então ele libera um monte de toxina na carne que isso a gente tá comendo junto. (E01)

Uma das entrevistadas, devido, segundo ela, à orientação de uma nutróloga, atribuiu a característica de conter "muito hormônio" exclusivamente à carne de frango, justificada pelo fato do frango engordar muito rápido. De fato, na avicultura de corte moderna, consegue-se que um frango esteja pronto para o abate em cerca de 45 dias. Todavia, esse período curto é resultado de avanços técnicos no que diz respeito à genética, manejo sanitário, ambiência e nutrição, com destaque para o uso de aditivos (probióticos, prebióticos e antibióticos) como promotores de crescimento na dieta. Francisco et al. (2007) apontam que a utilização de hormônios para acelerar o crescimento de frangos é o grande mito que envolve a avicultura moderna brasileira, e que $89 \%$ dos consumidores de carne de frango da cidade de Porto Alegre acreditam que ela contenha hormônio. Bueno et al. (2009), ao avaliarem o conhecimento de cardiologistas, endocrinologistas e nutricionistas sobre o uso de hormônios na dieta de frangos de corte, verificaram que quase $70 \%$ dos entrevistados responderam em alguma parte da pesquisa que existe o uso de hormônio nas granjas de frangos de corte, e que sua utilização pode acarretar problemas de saúde aos consumidores.

Faz menos mal do que a outra, segundo minha nutróloga. Ela que me orientou que eu comesse mais carne de porco ao invés de frango, que tem a mídia aí no frango, mas ela fala que a carne de porco faz menos mal que a de frango. Porque o frango eu acho que engorda em poucos dias, né. Então tem muito hormônio, muito tóxico, e aí ela sugere não comer, o mínimo possível. (E21)

Bem como as representações sociais do consumo de carne variam circunstancialmente, tendo como alicerce, ora a saúde, ora o paladar, quando emerge o fator econômico, mais especificamente o preço da carne, o mesmo parece ocorrer. Ela transita de item básico, de importante e necessário valor nutricional, para opcional e de luxo quando se evidencia a questão econômica. Para uma das entrevistadas, por exemplo, a carne seria fonte importante de 
nutrientes, sendo preciso comer "nem que seja um pedaço, todos os dias". Em outro momento da mesma entrevista, quando surge ocasionalmente a questão financeira, sua posição é de que, se não houver possibilidade de compra da carne, "não tem nada a ver", pois outros alimentos atenderiam à necessidade.

Da mesma forma, na pesquisa de Garcia (1997a), um mesmo entrevistado, quando se refere à comida de sua casa, coloca-a como sendo a melhor e a preferida. Em outra ocasião, ao falar de sua experiência com as refeições feitas fora de casa, o entrevistado diz que come melhor fora de casa. A autora utilizou a expressão "representações mutantes" para tais representações, explicando que os elementos constituintes das representações sociais convivem em estruturas flexíveis, adaptando-se às circunstâncias, ao gosto, aos valores etc. Entretanto, apesar da flexibilidade, não se pode considerar a existência de representações falsas, uma vez que todas elas respondem às necessidades da existência humana de diferentes formas e condições dadas (MINAYO, 2007).

\section{Carne vermelha $\mathrm{x}$ carne branca}

Ficou clara a diferença existente entre as representações sociais do consumo da carne vermelha e da branca quando se discute saúde. Mais uma vez, a vermelha apropria para si os significados dados à carne. Identificou-se nos discursos a atribuição a ela dos malefícios à saúde advindos do consumo de carne anteriormente discutidos. A carne branca, ao contrário, teve seu consumo fortemente relacionado à saúde. Salinas (2002) chama atenção para a composição das gorduras da carne de pescados, que se diferenciam bastante das contidas na generalidade dos alimentos de origem animal. Inversamente ao que é peculiar nessas últimas, a característica que predomina é a insaturação, com destaque para a presença do ômega-3. Com base principalmente nessa diferença, a carne de peixe é rotineiramente apontada no meio científico como mais saudável.

O ideal é comer carne de peixe, carne de frango, que é carne branca. Carne vermelha faz bem mais... o teor dela é bem mais... prejudica bem mais a saúde a carne vermelha. (E23)

\section{Carne e proteína}

Foi bastante evidente a representação social da carne como inquestionável fonte de proteínas, representação certamente ancorada na ciência. Porém, mesmo a carne sendo, no meio científico, reconhecida como importante fonte de muitos 
outros nutrientes essenciais ao bom funcionamento do organismo humano, a proteína é soberana nos discursos.

A carne é proteína. (E19)

Variações ocorreram apenas no que diz respeito à possibilidade de outros alimentos conseguirem suprir com mesma qualidade as necessidades proteicas do organismo humano. Nesse ponto, dois entrevistados demonstraram opiniôes distintas. Em verdade, segundo Slywitch (2010), a alimentação vegetariana pode cumprir tão bem a função de fornecimento de proteínas quanto uma com a inclusão da carne.

A melhor proteína é a animal. A soja não substitui, quem diz que substitui é balela.

Alguém aí diz que substitui. Tem a soja, a proteína vegetal, né? Mas isso não está provado. Pra animal, como ração animal, é uma excelente proteína. Pra produzir... proteína vegetal pra produzir proteína animal, não é isso? (E16)

[...] Todas as proteínas, o que eles dizem necessário pra viver utilizando carne, hoje já se encontra em outros meios, outras formas, outros alimentos assim. (E03)

Muito embora a carne branca seja representada como mais saudável que a vermelha, quando o tema em questão é "proteína”, ficou evidente em algumas falas a representação desta como possuidora de valor proteico superior, aquela que contém a tão clamada proteína animal. Entretanto, segundo Sailnas (2002), os conteúdos proteicos das diferentes carnes assemelham-se. Uma diferença estaria na carne de peixes, que, devido à quantidade menor de tecido conectivo e, dentro dele, à proporção muito menor de elastina que de colágeno, possui menor dureza e maior digestibilidade. Tais características determinam menor tempo de permanência no estômago, saciando menos que a carne de gado, o que pode explicar, pelo menos em parte, a representação social identificada.

$\mathrm{O}$ organismo precisa de pelo menos duas vezes por semana a carne vermelha por causa da proteína animal. (E21)

\section{O porco e sua carne: os grandes vilóes}

Chamou bastante atenção nesta pesquisa a forte presença de representações sociais negativas relativas ao suíno e a sua carne. Ela carrega o estigma de possuir teores de gordura perigosamente mais elevados que as outras, e ser higienicamente inadequada e potencial transmissora de doenças. $\mathrm{O}$ próprio porco foi tido por uma das entrevistadas como um animal "mais sujo", inclusive 
sua carne. Faria et al. (2006) estudaram o mercado consumidor de carne suína e derivados em Belo Horizonte, e verificaram que 38,4\% dos consumidores acreditam que a carne suína in natura e derivados sejam perigosos à saúde pelo excesso de gordura ou de colesterol, e $27,8 \%$ por transmitir doenças. Segundo os autores, o consumo de carne de porco no Brasil é baixo quando comparado a outros países, sobretudo europeus, e pode estar relacionado à persistência dessas representações em nossa sociedade.

Segundo Roppa (2010), ocorre entre os consumidores o desconhecimento em relação aos intensos trabalhos de melhoria nas áreas de genética, nutrição, manejo e sanidade que foram efetuados pelos criadores de suíno ao longo das últimas décadas. Pressionados por uma melhor produtividade para tornar a espécie economicamente mais viável e pelas exigências da população por um animal com menos gordura, devido à substituição desta pelos óleos vegetais, os técnicos e criadores passaram a desenvolver um novo tipo de suíno.

$\mathrm{O}$ autor faz a diferenciação entre "porco" e "suíno". O “porco" seria o animal rústico criado sob métodos rudimentares, sem condições higiênico-sanitárias adequadas, a fim de produzir carne e banha. Já o "suíno" seria o animal geneticamente melhorado, criado de modo tecnificado, com manejo nutricional e higiênico-sanitário adequados, para produzir carne de qualidade, segura e com teor reduzido de gordura, inclusive com níveis de colesterol comparados aos da carne bovina e de frango, sendo que alguns cortes apresentam até níveis inferiores. Entretanto, embora haja esforços da indústria e de associaçôes de criadores para que essa diferenciação penetre o pensamento dos consumidores, verificou-se que as representações sociais negativas da carne suína ainda resistem.

A carne suína, [como] muito pouco. Suína é muito pouco, porque faz muito mal, tem muita gordura. (E29)

Carne de porco não [como]. Carne de porco eu tenho medo. Medo das doenças que provoca. Eu perdi um amigo com solitária na cabeça. (E12)

Por exemplo, a carne de porco tem muita bactéria. (E17)

Porque não gosto. Assim, do próprio bichinho mesmo eu não gosto dele, então não como. (...) Eu acho ele porco mesmo, entendeu? Também sempre falaram que é um animal mais sujo, da própria carne mesmo. (E10)

É interessante lembrar que, na língua portuguesa, a palavra "porco" pode significar o animal suíno ou servir de adjetivo para "sujo", "imundo", "sem higiene". Esse fato parece corroborar para a perpetuação das representações 
sociais da carne suína identificadas. Como se percebe na fala mostrada acima, segundo a entrevistada, o porco é "porco mesmo".

Vale destacar que, por dois entrevistados, foi utilizado, para caracterizar a carne de porco, o sistema de classificação dos alimentos operante popularmente no Brasil descrito por Woortmann (1978). Com base nas oposições quente/ frio e reimoso/descarregado, a carne de porco foi apontada como "reimosa" e "quente". De acordo com o autor, em Belo Horizonte, comidas "quentes" são as que "desandam a pessoa", provocando diarreias e distúrbios estomacais ou intestinais. Já a "reima” trata-se de uma qualidade que torna o alimento "ofensivo" para certos estados do organismo.

E34: Carne de porco, a gente consome em ocasiões especiais, porque é uma carne mais gordurosa. Uma carne mais reimosa, entendeu? Meu marido não se adapta muito bem.

P: O que significa a carne ser reimosa?

E34: É uma carne mais gordurosa, que faz mal pro organismo. Ataca o fígado. Por isso que a gente não consome.

E22: [...] A carne de porco é muito reimosa também.

P: Muito o quê?

E22: Reimosa, uma carne muito quente.

\section{Conclusões}

A teoria das representações sociais, aliada à metodologia qualitativa, mostrouse, neste trabalho, ser alicerce bastante útil e adequado para a pesquisa do caráter sociocultural do consumo de carne. Os resultados mostraram que as representações simbólicas não são simples coadjuvantes no processo alimentar de consumo da carne. Pelo contrário, tais representações não somente estão fortemente presentes, como atuam na compreensão da realidade e orientam práticas e comportamentos, o que de certa forma já era esperado, uma vez que são componentes atribuídos às representações sociais.

Constatada, portanto, a importância do fator cultural no que diz respeito ao consumo da carne, espera-se dos profissionais de saúde cujas atribuições passem pela alimentação uma visão ampliada dessa realidade, para não correrem o risco de suas ações serem pautadas num tecnicismo reducionista.

$\mathrm{O}$ conhecimento das representações sociais do consumo de carne pode também ser proveitoso tanto para consumidores e indústria da carne, quanto 
para pessoas, grupos e entidades defensoras do seu não consumo. Estratégias

de marketing podem ser elaboradas pela indústria da carne para reforçar representações positivas e combater informações equivocadas que alimentam representações negativas. Defensores do não consumo de carne podem traçar planos mais eficientes para divulgação e esclarecimento de suas ideias e teorias, sejam elas de base nutricional, ecológica, religiosa ou ética. ${ }^{1}$

\section{Referências}

BARDIN, L. Análise de Conteúdo. Lisboa: Ediçôes 70, 2008, 281p.

BUENO, P.V. et al. Avaliação com profissionais da área da saúde sobre o uso de hormônios na dieta de frangos de corte. In: SIMPÓSIO DE CIÊNCIAS DA UNESP-DRACENA. 5. 2009, Dracena. Anais eletrônicos..., Dracena: UNESP- Dracena, 2009. Disponível em: $<$ http://www.dracena.unesp.br/eventos/sicud_2009/anais/monogastricos/032_2009.pdf> Acesso em: 04 fev 2010.

CANESQUI, A.M.; GARCIA, R.M.D. Uma introdução à reflexão sobre a abordagem sociocultural da alimentação. In: . Antropologia e Nutrição: um diálogo possível. Rio de Janeiro: Fiocruz, 2005. p.9-19.

CARNEIRO, H. Comida e Sociedade: uma história da alimentação. Rio de Janeiro: Campus, 2003. 185p.

DAMATTA, R. O que faz o Brasil, Brasil? Rio de Janeiro: Rocco, 1984. 126p.

. Sobre o simbolismo da comida no Brasil. Correio da UNESCO. v.15, n.7, p.21-23, 1987.

FARIA, I.G.; FERREIRA, J.M.; GARCIA S.K. Mercado consumidor de carne suína e derivados em Belo Horizonte. Arq. Bras. Med. Vet. Zootec., v.58, n.2, p.251-256, 2006.

FIDDES, N. Meat: a natural symbol. London: Routledge, 1991. 261p.

FILGUEIRAS, B.S.C. Do Mercado Popular ao Espaço de Vitalidade: O Mercado Central de Belo Horizonte. 2006.86f. Dissertação (Mestrado em Planejamento Urbano e Regional) Universidade Federal do Rio de Janeiro, Rio de Janeiro, 2006.

FRANCIONE, G.L. Rain Without Thunder: The Ideology of the Animal Rights Movement. Philadelphia: Temple University Press, 1996, 269p.

FRANCISCO, D.C. et al. Caracterização do consumidor de carne de frango da cidade de Porto Alegre. Ciênc. Rural, v.37, n.1, p.253-258, 2007.

GARCIA, R.W.D. Representaçôes sociais da comida no meio urbano: algumas consideraçôes para o estudo dos aspectos simbólicos da alimentação. Cad. Debate, v.2, n.2, p.12-40, 1994. . Práticas e comportamento alimentar no meio urbano: um estudo no centro da cidade de São Paulo. Cad. Saúde Públ., v.13, n.2, p.455-467, 1997a. 
Representações Sociais da alimentação e saúde e suas repercussões no comportamento alimentar. Physis, v.7, n.2, p.51-68, 1997 b.

GONÇALVES, J.R.S. A fome e o paladar: a antropologia nativa de Luis da Câmara Cascudo. Estud.hist., v.1, n.33, p.40-55, 2004.

ISHIGE, N. O homem, o comensal. Correio da UNESCO. v.15, n.7, p.18-21, 1987.

MACIEL, E.M. Uma cozinha à brasileira. Estud. hist.,v.1, n.33, p.25-39, 2004.

MINAYO, M.C.S. O desafio do conhecimento: pesquisa qualitativa em saúde. 10 ed. São Paulo: Hucitec, 2007, 406p.

MINTZ, S.W. Comida e antropologia: uma breve revisão. Rev. bras. Ci. Soc., v.16, n.47, p.31-41, 2001.

MOSCOVICI, S. Representações Sociais: investigações em psicologia social. Petrópolis: Vozes, 2003, 404p.

RIAL, C. Fast-food. In: CONGRESSO BRASILEIRO DE GASTRONOMIA E SEGURANÇA ALIMENTAR 1., 2004, Brasília. COLETÂNEA DE PALESTRAS..., Brasília: UNB, 2004. p. 250-282.

ROPPA, L. Carne suina: mitos e verdades. Disponível em: <http://www.sips.com.br/ manual_download.php?id_arquivo=275>. Acesso em: 06 fev 2010.

ROSA, M.V.F.P.C.; ARNOLDI, M.A.G.C. A entrevista na pesquisa qualitativa: mecanismos para validação de resultados. Belo Horizonte: Autêntica, 2006.112p.

SALINAS, R.D. Alimentos e nutrição: introdução à bromatologia. 3.ed. Porto Alegre: Artmed, 2002.

SILVA, J.K. et al. Alimentação e cultura como campo científico no Brasil. Physis, v.20, n.2, p.413-442, 2010.

SLYWITCH, E. Alimentação sem carne: guia prático. São Paulo: Alaúde, 2010. 112p.

STRONG, R.C. Banquete: uma história ilustrada da culinária, dos costumes e da fartura à mesa. Rio de Janeiro: Jorge Zahar, 2004. 300p.

WOORTMANN, K. Hábitos e ideologias alimentares de grupos sociais de baixa renda: relatório final. Brasília: UNB, 1978. 114p. (Série Antropologia 20).

. O sentido simbólico das práticas alimentares. In: CONGRESSO BRASILEIRO

DE GASTRONOMIA E SEGURANÇA ALIMENTAR 1., 2004, Brasília. Coletânea de Palestras..., Brasília: UNB, 2004. p. 1-43.

\section{Nota}

${ }^{1}$ Este estudo é baseado na dissertação de mestrado do primeiro autor, intitulada Representaçôes sociais do consumo de carne, Belo Horizonte - MG - 2009. G.S. de Barros participou de todas as etapas referentes à pesquisa e elaboração do artigo; J.N.C. Meneses e J.A. da Silva participaram da idealização da pesquisa, análise de dados e redação do artigo. 


\section{Social representations of meat consumption in the city of Belo Horizonte}

The goal of this study was to identify social representations of meat consumption in Belo HorizonteMG, through qualitative methodology. Semi-structured interviews were conducted with 34 Belo Horizonte Central Market goers and analyzed based on the content analyze technique. It was verified that the taste for meat is mainly represented as a cultural construction and also that meat takes a central part on meals, sometimes working as an element of social cohesion. The Lenten abstinence from meat showed to be emptied of its original meaning, perpetuating itself as a simple tradition or Catholic Church norm. It was observed that in several occasions red meat contained the meaning of "meat" exclusively in itself. There were several representations towards health, being meat consumption represented as being healthy or not healthy depending on the circumstance. Furthermore, when costs were approached, meat transited from a necessary to an optional item. Meat was strongly identified as a source of protein and white meat was considered healthier than red meat. Pork meat was represented as fatty and as a potential disease carrier. In general social representations of meat consumption were shown to be independent of the representations of farm animals. It is expected from health professionals to take into account the complexity and importance of the cultural factor in the meat consumption in order to mitigate the risk of guiding their actions based on a reductionist technicality. Results may also be useful to meat industry as well as to non-consuming defenders.

Key words: meat consumption; social representations; qualitative research. 